\title{
Henoch Schonlein Purpura, with Special Reference to Renal Involvement: An Experience at SKIMS
}

\author{
Bashir A. Charoo, M.D., Qazi lqbal, M.D., Mushtaq Ahmad, M.D., Akhtar Rasool Baba, M.D. \\ Department of Pediatrics and Neonatology, Sher-i-Kashmir Institute of Medical Sciences, Soura, Srinagar, Kashmir.
}

\section{A B S T R A C T}

BACKGROUND: Henoch Schonlein Purpura (HSP) or anaphylactoid purpuracharacterized by purpura, arthritis, abdominal pain, glomerulonephritis and gastrointestinal bleed, is one of the most common types of vasculitis of childhood. We see patients of HSP from all parts of Kashmir in our department at Sher-i-Kashmir Institute of Medical Sciences (SKIMS). Many of these patients develop complications and invariably have critical hospital course.

OBJECTIVES: To study the epidemiology, clinical spectrum and outcome of HSP patients seen at SKIMS.

METHODS: Patients of HSP who visited our hospital over last 6 years, between November 2005 and October 2011, were studied for the epidemiological aspects, clinical presentation, complications, duration of purpura and response to treatment in the our Pediatric department.

RESULTS: HSP patients constituted approximately $0.32 \%$ of total admissions. Purpura was present in all patients, $83.95 \%$ had arthritis, $80.24 \%$ had abdominal symptoms, $35.80 \%$ patients had persistent purpura and $34.56 \%$ patients had nephritis

CONCLUSION: Majority of HSP patients are in the age group of 6-12 years. Renal involvement is more common in older age group; steroids seem have a role in preventing the severity of nephritis in HSP. JMS 2012;15(2):128-31

Key words: Henoch Schonlein Purpura, arthritis, glmerulonephritis, Gl bleed

Henoch Schonlein Purpura (HSP), an IgA mediated autoimmune vasculitis is one of the most common types of vasculitis of childhood, affects small blood vessels, especially capillaries, postcapillary venules and arterioles. ${ }^{1,2}$ It is characterized by purpura, arthritis, abdominal pain, glomerulonephritis and gastrointestinal bleed. It has been described by Willan in $1808 .^{3}$ Schonlein in 1837 described the diagnostic triad of purpuric rash, arthritis and hematuria. ${ }^{4}$ It

\section{Correspondence:}

Dr. Qazi lqbal

Associate Professor

Department of Pediatrics and Neonatology, Sher-i-Kashmir Institute of Medical Sciences Soura, Srinagar, Kashmir.-190011.

E-mail: drqaziiqbal@yahoo.co.in was named as anaphylactoid purpura in $1948 .^{6}$ Henoch described its association with bloody diarrhea and proteinuria in $1874 .^{5}$ The disease occurs mostly in children in the age group of 3 to 15 years. It is rare in infants and toddlers. $^{7}$ Global incidence is 0.2 to 20.4 cases per 100,000 children per year with male to female ratio of 1.5 to $2: 1$. $^{8,9} \mathrm{It}$ occurs more frequently during winter months. ${ }^{10}$ Two third of affected children have history of upper respiratory tract infection in the preceding 1 to 3 weeks. Group A betahemolytic streptococcus, Other bacteria, mycoplasma, viruses and vaccinations have been implicated as a trigger for the disease. ${ }^{11-15}$ Insect bites, exposure to drugs, pesticides and dietary allergens are other causative factors. ${ }^{16}$ Deposition of immune complexes of IgA type in the kidneys, intestine, skin and other target organs suggests its immune mediated 
origin. ${ }^{17}$ Leukocytoclastic vasculitis is the predominant inflammatory reaction in $\mathrm{HSP}^{18}$ Disease has acute clinical onset but diagnostic manifestations appear over days to weeks, $100 \%$ patients have palpable purpura. Gastrointestinal manifestations occur in approximately $70 \%$ cases within one week to one month. $50 \%$ patients develop arthritis, rarely it may precede purpura by 1 or 2 days. ${ }^{19}$ Glomerulonephritis occurs in $30-40 \%$ cases; in less than $10 \%$ it poses a serious problem. ${ }^{10}$ It needs to be differentiated from SLE, thrombocytopenic purpura, other causes of glomerulonephritis, sepsis and DIC. ${ }^{18}$ Short term morbidity, in HSP patients, is associated with gastrointestinal symptoms while as long term morbidity is related to renal involvement. Although HSP is self-limiting disease and complete resolution being the norm, persistent proteinuria imparts the worst outlook. $1-5 \%$ patients progress to end stage renal disease. Some HSP patients need long term follow up for renal disease.

\section{Methods}

Patients of HSP who visited our hospital between November 2005 and October 2011 were studied. HSP was provisionally diagnosed if patient had purpuric rash and abdominal pain (without thrombocytopenia). History of abdominal pain, gross hematuria, per rectal bleeding, joint pain, and preceding events like infections, vaccination, drug intake and insect bite was asked. Type and distribution of rash were noted. Patients were examined for edema, larger skin bleed, lymphadenopathy, scrotal edema, testicular torsion, headache, seizures, altered sensorium, ocular involvement, Guillain-Barre syndrome and malena. Patients with disabling arthritis and those with bloody stools were considered to have severe symptoms. Purpura persisting beyond one month was classified as persistent purpura.

Complete blood counts, ESR, urine examination, 24 hours urinary protein, throat swab culture, blood culture, kidney function test, antinuclear antibody, abdominal ultrasound and serum IgA were done. Abnormal reports were cross checked. Depending upon the hospital course, in some patients several investigations were repeated and certain additional investigations were also done. Barium enema for intussusception, scrotal ultrasonography for possible testicular torsion and renal biopsy for persistent nephritic syndrome were done in selected patients.

Those patients with provisional diagnosis of HSP whose hospital course and investigations revealed a different diagnosis were excluded from the study.

HSP patients were given supportive treatment in the form of hydration and nutrition. Antibiotics to control infection and antihypertensive drugs and analgesics were given according to the signs and symptoms of the patient. Glucocorticoids were not used as a universal mode of treatment. ${ }^{16}$ Steroids and immunoglobulins were used in patients with severe gastrointestinal disease or hemorrhage, patients with severe arthritis, patients who had persistent rash for more than a month and patients who developed nephrotic picture. ${ }^{23,24}$ Patients were followed up for a period of one year.

\section{Results}

Provisionally 49 patients were diagnosed with HSP out of a total of 13168 patients admitted during a period of six years; during their hospital stay diagnosis was revised in six of them. So 43 patients with final diagnosis of HSP were studied during this period. Majority (24 patients) were in the age group of 6-12 years with male: female ratio of $1.7: 1$, while as only 5 patients were above 12 years; among them three were male. Fourteen patients were below 6 years of age with 9 males and 5 females. All the 43 patients had purpuric rash at the time of admission in the hospital. In 4 (9.30\%) patients purpuric rash was preceded by abdominal pain. Fifteen $(34.88 \%)$ patients had persistent purpura (purpura for more than a month); 11 of them were more than 6 years, and 4 were below 6 years of age. Fourteen (32.55\%) patients developed renal involvement, 12 of them were with persistent purpura. Arthritis occurred in 36(83.72\%) patients and severe joint symptoms were present in $14(32.55 \%)$ patients. Abdominal symptoms were present in $34(79.06 \%)$ patients. Seven (16.27\%) patients developed gastrointestinal bleed; three of these patients had prolonged GI bleed (episodes of recurrent massive malena and persistent hematochezia) with persistent purpura in one of them. One of them needed surgical intervention. Three patients developed intussusception. Overt pancreatitis, with highly elevated amylase, occurred in 2 patients and orchitis in 3 patients. Headache occurred in 8 patients, 3 of them had it at admission and 5 developed it during hospital stay. Five patients with headache had hypertension. Three patients had seizures during the disease; CT brain was done in them and it was normal in two of them, while as in one patient who had hypertension also CT brain revealed intracranial bleed. Lymphadenopathy with hepatosplenomegaly was seen in five patients and lymphadenopathy alone in two patients. Ultrasonography demonstrated moderate ascites in 4 patients, one among them had associated right sided pleural effusion and same patient developed progressive renal disease and was treated with cyclophosphamide. Out of the 43 patients 18 received prednisolone, 5 of them for severe abdominal symptoms that did not respond to supportive therapy, 3 were with pancreatitis or orchitis, 8 were with severe joint symptoms. Four patients with early renal involvement received methylprednisolone, 3 of them showed improvement in the nephritis picture, one patient had persistent hematuria; however, none of them had progression of renal disease during one year follow up.

Platelet count was in the normal range of $1,50,000$ to $4,50,000$ in 38 patients. Five patients had platelets more than $4,50,000$ per cubic mm. Six patients had leukocytosis of more than 20,000 per cubic mm. Hemoglobin was less than 9 $\mathrm{gm} / \mathrm{dL}$ in 6 patients; in most of them it was due to gastrointestinal blood loss. Stool examination for occult blood was 
positive in 12 patients, who constituted $35.29 \%$ of patients with abdominal pain.

Rheumatoid factor was positive in 3 patients out of them 2 had nephritis. IgA levels were raised in $26(60.46 \%)$ patients. Abdominal ultrasound revealed distended bowl loops in $31(72.09 \%)$ patients. MRI brain done in seven patients with seizures or severe headache revealed cerebral vasculitis pattern, one of them had intracranial bleed and infarction.

\section{Discussion}

Improvements in medical practice has reduced the frequency of HSP admissions; $0.60 \%$ HSP admissions in this study is little higher than what has been reported from some advanced medical centers. ${ }^{9}$ In our study majority of the patients were above 6 years, while as disease has been reported more commonly in under 7 years. ${ }^{18}$ Very few patients gave the history of preceding infections, though $28(65.11 \%)$ patients were seen during winter and early spring when respiratory tract infections are very common in Kashmir valley. Purpura has been the most common presentation and the patients with more severe and persistent purpura are actually more prone to have the systemic complications including renal disease, central nervous system involvement, and gastrointestinal complications. In our study $32.55 \%$ patients had renal involvement which is consistent with other studies. ${ }^{26}$ While as some studies have reported renal involvement in $30 \%-80 \%$ of HSP patients. ${ }^{27}$ Renal involvement was more common in the higher age group than in under 6 years. Renal involvement in HSP is associated with several factors such as age at onset, severity of abdominal symptoms, and recurrence of purpura and whether corticosteroids have or have not been used. ${ }^{28}$ Though steroids were not always used specifically for nephritis, renal involvement was less common and less severe in the patients who received the steroids earlier in the disease, whatever was the indication for use of steroids. Similar findings have been reported by Reinehr $\mathrm{T}$ and Kawasaki Y. ${ }^{29,30}$

Steroids, both prednisolone and methylprednisolone and IVIG have a role in preventing and arresting the progression of renal disease in HSP patients.

\section{References}

1. Tizzard EJ. Henoch-Schonlein purpura. Arch Dis Child 1999;80:380-83.

2. Mrusek S. Kruger M. Greiner P, et al. HenochSchonlein purpura. Lancet 2004;363:1116.

3. Willan R. On Cutaneous Diseases. London. J. Johnson 1808.

4. Schonlein JL. Allegemeine and specielle pathologic and therapie, 3rd. ed. Herisau, Germany, Literatucomptoir, 1837.
5. Gairdner D. The Schonlein-Henoch syndrome (anaphylactoid purpura). QJMed 1948;17:95.

6. Al Sheyyab M, El Shanti H, Ajlouni S, et al. The clinical spectrum of Henoch Schonlein purpura in infants and young children. Eur J Pediatr 1995;154:969-72.

7. Saulsbury FT. Epidemiology of Henoch-Schonlein purpura. Cleve Clin J Med 2002;69:S1187-S89.

8. Calvino MC, Llorca J, Garcia Porrua C, et al. HenochSchonlein purpura in children from northwestern Spain: A 20-year clinical and epidemiological study. Medicine (Baltimore) 2001;80:279-90.

9. Erdstrom Halling SF, Soderberg MP. Henoch-Schonlein nephritis: Clinical findings related to renal function and morphology. Pediatr Nephrol 2005;20:46-51.

10. Masuda M, Nakanishi K, Yoshizawa N, et al. Group A streptococcal antigen in the glomeruli of children with Henoch-Schonlein nephritis. Am J of Kidney Dis 2003; 41:366-70.

11. Lambert EM, Liebling A, Glusac E, et al. HenochSchonlein purpura following a meningococcal vaccine. Pediatrics 2003;112: e491.

12. Kalyoncu M, Odemis E, Yaris N, et al. Association of Henoch-Schonlein purpura with Varicella zoster. Indian Pediatr 2003;20:274-75.

13. Islek I, Kalayci AG, Gok F, et al. Henoch-Schonlein purpura associated with Hepatitis A infection. Pediatr Int 2003;45:114-16.

14. Gonzalez-Gay MA, Calvino MC, Vazquez-Lopez ME, et al. Implications of upper respiratory tract infections and drugs in the clinical spectrum of HenochSchonlein purpura in children. Clin Exp Rheumatol 2004;22:781-84.

15. Saulsbury FT. Henoch-Schonlein purpura in children, Report of 100 patients and review of the literature. Medicine (Baltimore) 1999;78:395-409.

16. Yang YH, Huang MT, Lin SC, et al. Increasing transforming growth factor-beta- screening $\mathrm{T}$ cells and IgA anticardiolipin antibody levels during acute stage of childhood Henoch-Schonlein purpura. Clin Exp Immunol 2000;122:285-90.

17. Murali NS, George R, John GT, et al. Problems of classification of Henoch-Schonlein purpura, An Indian perspective. Clin Exp Derematol 2002;27:260- 63.

18. Saulsbury FT. Clinical update, Henoch-Schonlein purpura. Lancet 2007;369:976-78.

19. Coppo R, Andrulli S, Amore A, Gianoglio B, Conti G, Peruzzi L, et al. Predictors of outcome in HenochSchonlein nephritis in children and adults. Am J Kidney Dis 2006;47:993-1003.

20. Narchi H. Risk of long term renal involvement and duration of follow up recommended for Henoch-Schonlein purpura with normal or minimal urinary findings, A systematic review.Arch Dis Child 2005; 90:916-20. 
21. Ioannides AS, Turnock R. An audit of management of the acute scrotum in children with Henoch-Schonlein purpura.J R Coll Surg Edinb 2001;46:98-99.

22. Paolini S, Ciappetta P, Piattella MC, et al. HenochSchonlein syndrome and cerebellar hemorrhage: Report of an adolescent case and literature review. Surg Neurol 2003;60:339-42.

23. Wu TT, Sheu SJ, Chou IC, et al. Henoch-Schonlein purpura with bilateral central retinal artery occlusion, BrJ Ophtholmol 2002;86:351-52.

24. Dillon MJ. Henoch-Schonlein purpura, treatment and out come. Cleve Clin J Med 2002;69:SII121-SII23.

25. Wang L, Huang FC, Ko SF, Cheng MT. Successful treatment of mesenteric vasculitis caused by HenochSchonlein purpura with methylprednisolone pulse therapy. Clin Rheumatol 2003;22:140-42.

26. Hamadan KM, Baraqawi MA. Henoch-Schonlein purpura in children, Influence of age on the incidence of nephritis and arthritis. Saudi Med J 2008;29:549-52.

27. Van ES, Kauffmann RH, Valentijin RM. HenochSchonlein purpura, Pediatric Nephrology-2nd. Ed. 1987, edited by Holliday MA, Barratt TM, Vernier RL, Baltimore, Williams and Wilkins, 492-98.

28. Kaku Y, Nohara K and Honda S. Renal involvement in Henoch-Schonlein purpura: A multivariate analysis of prognistic factors. Kidney Int 1998; 53:1755-59.

29. Reinehr T, Burk G, Andler W. Does steroid treatment of abdominal pain prevent renal involvement in Henoch-Schonlein purpura. J Pediatr Gastroenterol Nutr 2000;31:323-24.

30. Kawasaki Y, Suzuki J, Nozawa R, et al. Efficacy of methylprednisolone and urokinase pulse therapy for severe Henoch-Schonlein nephritis. Pediatrics 2003; 111:785-89. 